\title{
Mediación como profesión emergente: actualidad formativa desde la Educación Superior
}

\author{
Iglesias Ortuño, Emilia ${ }^{1}$; Pastor Seller, Enrique²; Rondón García, Luis Miguel ${ }^{3}$
}

Recibido: 16 de diciembre de 2016 / Aceptado: 4 de abril de 2017

Resumen. La mediación es una actividad profesional emergente que tiene escasamente definidas las competencias precisas para su ejercicio profesional, hecho que afecta a las estrategias formativas actualmente vigentes en el ámbito de la Educación Superior. Por lo tanto, es necesario trabajar para la constitución de un currículo académico común que favorezca una formación homogénea, de calidad y relevante para el reconocimiento social de una profesión emergente. Mediante un estudio metodológico cualitativo con un diseño de investigación descriptiva que ha empleado la técnica de análisis documental haciendo uso del paquete informático MAXqda hemos estudiado las estrategias docentes actualmente vigentes en Cataluña y hemos identificado las principales competencias para el ejercicio profesional mediador que podrían sentar las bases de modelos educativos de reconocimiento nacional.

Palabras clave: Mediación; competencia; educación superior; planificación académica; formación profesional.

\section{[en] Mediation as an emerging profession: current training from Higher Education}

\begin{abstract}
Mediation is an emerging professional activity that has poorly defined his own competences for his professional labour, fact that concern to the current training strategies from Higher Education. Because of that, it is necessary to work towards the constitution of a common academic curriculum that favours homogeneous, quality and relevant training for the social recognition of an emerging profession. Through a qualitative methodological study with a descriptive research design that has apply the documentary analysis by MAXqda software, we have studied the current training strategies in Catalonia and we have identified the core competences to the mediator labour that could be a foundation for nationals teaching models.
\end{abstract}

Keywords: Mediation, competence; higher education; academic planning; professional training.

\footnotetext{
${ }^{1}$ Universidad Autónoma de Nuevo León (México). eiglesiasortuno@gmail.com,

${ }^{2}$ Universidad de Murcia (España). epastor@um.es

${ }^{3}$ Universidad de Granada (España). lmrondon@ugr.es
} 
Sumario. 1. Introducción. 2. Fundamentación Teórica. 3. La mediación como actividad profesional emergente. 4. Presentación del estudio. 5. Principales resultados del estudio. 6. Conclusiones y reflexiones finales. 7. Referencias bibliográficas.

Cómo citar: Iglesias Ortuño, Emilia; Pastor Seller, Enrique; Rondón García, Luis Miguel (2017). "Mediación como profesión emergente: actualidad formativa desde la Educación Superior", en Mediaciones Sociales, 16, 135-153-

\section{Introducción}

El Espacio Europeo de Educación Superior (En adelante EEES) introduce un conjunto de mejoras y modificaciones en el sistema educativo con el objetivo de garantizar la relación entre formación y realidad laboral, todo ello remarcando aspectos como la Deontología y la calidad. Estas modificaciones son recogidas en el denominado Proyecto Tuning, entre las que destacamos el aprendizaje por competencias. Indican González y Wagenaar (2003:15) "el EEES defiende la necesidad de instaurar el modelo de aprendizaje por competencias pues lo considera óptimo para permitir a los egresados conocer y comprender, saber cómo actuar y saber cómo ser para poder realizar una actividad profesional que dé respuesta a las demandas sociales". Las competencias en el ámbito académico, como extraemos de la obra de De Juanas y Fernández (2008), hacen referencia a aquellas que demanda el desempeño de una profesión. Las aportaciones de Echeverría (2005) nos conducen a identificar que la adquisición de las competencias hay que plantearla desde un enfoque holístico pues se conciben como el conjunto de conocimientos, procedimientos, capacidades y actitudes, que son complementarios entre sí de tal forma que los profesionales han de saber, saber hacer, saber estar y saber ser para actuar con la máxima eficacia y eficiencia en sus actuaciones profesionales.

\section{Fundamentación teórica}

La mediación es, en palabras de Pastor e Iglesias (2011:75), "un proceso mediante el cual las personas son capaces de gestionar positivamente sus conflictos, con el objetivo de encontrar soluciones eficaces", añaden Pastor y Huertas (2012:139) que "es además un proceso educativo basado en el diálogo y el respeto donde los terceros asumen la responsabilidad de su acción". La mediación, como actividad profesional emergente, dispone de una serie de normas reguladoras respecto a la formación específica que abarcan tanto el ámbito nacional, como las autonomías o el ámbito internacional europeo. Esta normativa, sin embargo, podría ser considerada escasa puesto que no acompañan a otro tipo de regulación específica de carácter formativo, como un Currículo profesional, un Libro Blanco o un Manual de procedimiento pedagógico. Este hecho puede deberse a la relativa juventud de la mediación como actividad profesional, problemática que puede afectar también a otras actividades profesionales en actual proceso de construcción. Esto supone para las profesiones emergentes una dificultad que genera títulos aparentemente similares, pero que carecen de una base de referencia que guíe su 
planificación, lo que supone la aparición de heterogeneidad entre la oferta formativa que deriva en diversidad en el conjunto de profesionales en activo.

Algunos autores como Folberg y Taylor (1996), Marshall (2006), García y Bolaños (2007), Rondón (2012) o Gorjón y Sáenz (2014) han estudiado el perfil de la persona mediadora y las funciones y habilidades precisas para el ejercicio de su rol, obteniendo una serie de habilidades necesarias para la intervención en mediación. A partir de esto han identificado una serie de competencias precisas para el ejercicio profesional mediador que podrían sentar las bases de un futuro currículo profesional o manual de referencia para la formación específica en la materia. Los autores proponen una serie de competencias desde su perspectiva de expertos que remarcan las principales habilidades que ha de tener la persona mediadora y determinan los conocimientos que es preciso adquirir para garantizar cada una de ellas. 
Tabla 1. Competencias y conocimientos de la persona mediadora según expertos.

\begin{tabular}{|c|c|c|}
\hline $\begin{array}{l}\text { Área } \\
\text { Competencial }\end{array}$ & Competencias & Conocimientos \\
\hline $\begin{array}{l}\text { Competencias } \\
\text { Generales }\end{array}$ & $\begin{array}{l}\text { Aquellas que permiten al } \\
\text { individuo ser activo en cuanto } \\
\text { al aprendizaje y al desarrollo de } \\
\text { su actividad educativa y } \\
\text { profesional: } \\
\text {-Conocimiento de las variables } \\
\text { de la comunicación } \\
\text {-Comprensión de los beneficios } \\
\text { de la colaboración de las } \\
\text { diferentes áreas de } \\
\text { conocimiento. } \\
\text {-Dominio de la Planificación } \\
\text {-Comprensión, análisis, crítica } \\
\text { y estudio. } \\
\text {-Adaptación de la teoría a la } \\
\text { práctica. }\end{array}$ & $\begin{array}{l}\text {-Teorías de la comunicación } \\
\text {-Habilidades de trabajo en } \\
\text { equipo } \\
\text {-Trabajo en equipo } \\
\text { multidisciplinar } \\
\text {-Planificación de la } \\
\text { intervención } \\
\text {-Habilidades y técnicas de } \\
\text { estudio } \\
\text {-Análisis de supuestos prácticos }\end{array}$ \\
\hline $\begin{array}{l}\text { Competencias } \\
\text { específicas }\end{array}$ & $\begin{array}{l}\text { Aquellas que permiten al } \\
\text { individuo aprender la profesión } \\
\text { de la mediación en cuanto a } \\
\text { base teórica y práctica. } \\
\text {-Dominio del conflicto } \\
\text {-Capacidad para desarrollar el } \\
\text { proceso de mediación, sus fases } \\
\text { y sus protocolos de actuación. } \\
\text {-Ejecución de las habilidades y } \\
\text { técnicas del mediador } \\
\text {-Desempeño del rol de } \\
\text { mediador. } \\
\text {-Distinción de roles con } \\
\text { respecto a otras disciplinas. } \\
\text {-Respeto del código ético } \\
\text { reconocido. }\end{array}$ & $\begin{array}{l}\text {-Teorías del conflicto } \\
\text {-Ciclo del conflicto } \\
\text {-Componentes del conflicto } \\
\text {-Estrategias de gestión de } \\
\text { conflictos } \\
\text {-Estilos de afrontamiento de los } \\
\text { conflictos } \\
\text {-El proceso de mediación y sus } \\
\text { fases } \\
\text {-Habilidades de mediación } \\
\text { como: escucha activa, } \\
\text { comunicación eficaz, } \\
\text { imparcialidad, neutralidad. } \\
\text {-Diferencias y similitudes entre } \\
\text { el mediador y otros } \\
\text { profesionales } \\
\text {-Estudio de los diferentes } \\
\text { Códigos de Conducta a partir } \\
\text { de la normativa europea. }\end{array}$ \\
\hline
\end{tabular}


Según observamos en la Tabla 1 sobre competencias y conocimientos de la persona mediadora, la propuesta educativa realizada por expertos conocedores en la materia que pretende servir de guía para las acciones formativas en materia de mediación, pone el foco de atención en la adquisición de las competencias que desde su perspectiva son precisas para el ejercicio del rol mediador. Así mismo proponen una serie de contenidos teóricos que puedan garantizar la adquisición de las mismas. El conocimiento de la propuesta académica que hacen los expertos sienta las bases para un estudio más detallado sobre las competencias precisas para el ejercicio profesional mediador, siendo el segundo paso el estudio de las competencias reflejadas desde el ámbito formativo.

\section{La mediación como actividad profesional emergente.}

El primer punto para comprender la construcción disciplinar de la mediación es la judicialización de los conflictos, entendida ésta como el requerimiento excesivo por parte de la ciudadanía de obtener una respuesta jurídica a todo tipo de conflictos. Este hecho supuso una importante crisis judicial que derivó en la concienciación sobre la pertinencia de nuevos métodos alternativos de gestión de conflictos que se ocuparan de varios aspectos: descongestionar la justicia, devolver la autonomía y participación a las partes y la promoción de la justicia social y la paz.

La mediación, al igual que otras profesiones emergentes, lleva aparejada una problemática que puede incidir de forma negativa en los procesos de construcción formativa y desarrollo disciplinar. Se trata de la falta de un currículo profesional estandarizado y reconocido que aporte un apoyo para la programación de acciones formativas y la definición de la ejecución profesional. Es decir, dado lo reciente de la mediación como actividad profesional, aún no existe un modelo competencial que defina el ejercicio profesional y que sirva de elemento determinante para la programación de acciones formativas. Este hecho representa para las profesiones emergentes la generación de títulos formativos específicos pero dispares entre sí que generan un conjunto dispar de profesionales egresados con concepciones diversas sobre la ejecución de su rol profesional. Esta disparidad afecta, además, a la identificación profesional por parte de la sociedad que no ubica con facilidad el nuevo perfil profesional mediador y que, por lo tanto, no lo incorpora al conjunto de agentes sociales a los que recurrir para el tratamiento de conflictos sociales.

La formación en mediación es motivo de debate y discusión debido a la variedad estructural que el propio término aglutina. Con variedad nos referimos a que la cuestión formativa en mediación incluye aspectos como: duración, composición, especialización, entrenamiento, evaluación y aplicación que son considerados de diversas formas según el espacio en que se realice la consulta. Esta variedad estructural genera una formación específica en mediación diversificada, poco cohesionada y con diferente estructura, orientación y resultados. Siendo el principal efecto un conjunto de profesionales heterogéneo y preparado de forma diferente para ejecutar la intervención profesional mediadora. 


\section{Presentación del estudio}

Como hemos indicado anteriormente, la mediación, como actividad profesional emergente carece de un currículo educativo determinado o un modelo competencial definido y de referencia para la creación y composición de las ofertas formativas específicas en la materia. Sin embargo, las aportaciones de los expertos así como el marco normativo que regula la mediación es España pueden actuar como elemento proveedor de directrices y recomendaciones. Además de las propuestas establecidas por los expertos y la legislación de referencia, las acciones formativas desarrolladas actualmente suponen un elemento relevante, pues presentan una estructura académica con elementos comunes más allá de las recomendaciones normativas que pueden disponer las bases para la creación de un modelo unificador además de su relevancia intrínseca al ser las generadoras de los futuros profesionales de la actividad mediadora. Por lo tanto, es de gran interés conocer la composición teórico-práctica de las ofertas formativas actuales específicas en mediación y contrastar esta composición con las aportaciones de los expertos para extraer los puntos en común, pues estos puntos comunes serían considerados elementos relevantes a tener en cuenta para el diseño de una acción formativa sobre mediación que aúne la percepción empírica con la realidad formativa.

El primer objetivo de este estudio es conocer la composición teórico-práctica de las ofertas formativas actualmente vigentes en Cataluña ejecutadas desde el ámbito universitario. Queremos conocer si existe un constructo común que pudiera sentar las bases para favorecer la homogeneización de la enseñanza de esta actividad profesional. Así mismo, el segundo objetivo de esta investigación es determinar la presencia de competencias en las acciones formativas actualmente impartidas en las universidades catalanas para determinar el grado de adaptación de esta profesión emergente al modelo de aprendizaje por competencias propio del EEES.

Las fuentes de información son las guías docentes y de título así como las fichas de acción formativa de las 19 acciones formativas vigentes y homologadas ejecutadas durante el curso académico 2015-2016 e impartidas en entidades universitarias públicas y privadas de Cataluña. Nos hemos centrado en esta comunidad pues es considerada la pionera en el desarrollo de la mediación y por ende la que contempla una mayor tradición formadora. Así mismo, hemos circunscrito nuestras fuentes de información al ámbito universitario al entenderse éste en relación directa con los nuevos modelos educativos del EEES.

La metodología diseñada para este trabajo ha sido cualitativa mediante un diseño descriptivo. El método de obtención de datos ha sido el análisis documental, empleando como instrumento una tabla de descriptores. Este análisis lo hemos realizado aplicando el paquete informático MAXqda en su versión 12.

\section{Principales resultados del estudio}

\section{- La incidencia de la formación en mediación en las universidades catalanas}

En este apartado mostramos los principales resultados obtenidos del proceso investigador relativos a la presencia de acciones formativas específicas en 
mediación actualmente vigentes en Cataluña. En las 12 universidades catalanas, tanto públicas como privadas, hemos detectado acciones de formación específicas sobre mediación en 7 de ellas (representando el 58\% de la totalidad de las universidades). En estas 7 universidades, una de ellas privada y otras 6 públicas, hemos identificado 19 acciones formativas actualmente vigentes durante el curso académico 2015-2016 y homologadas por el Centre de Mediació en Dret Privat de Cataluña ${ }^{4}$.

Del conjunto de acciones formativas estudiadas, destacamos que el grupo mayoritario (representando el $31 \%$ del total) se configura como master propio siendo su duración media mayoritariamente de 60 créditos ECTS y posee un carácter predominantemente presencial.

\section{- Constructo teórico-normativo}

Del análisis de las 19 acciones formativas vigentes durante el curso académico 2015-2016 en las universidades catalanas podemos decir que, como sugiere la normativa al respecto, los principales bloques de contenidos son: Normativa jurídica; Aspectos psicológicos; Deontología y Fases de la mediación, habilidades y técnicas. Tas el análisis de las ofertas formativas estudiadas presentamos los siguientes bloques de contenidos detectados: Bases teóricas de la mediación; Conflictología y ADR; Ámbitos de aplicación de la mediación; Metodología de Intervención (práctica); Planificación e investigación en mediación, siendo la siguiente la distribución de cada uno de ellos en el conjunto formativo de las universidades catalanas.

Tabla 2 Distribución de contenidos en la formación en mediación

\begin{tabular}{|l|l|}
\hline \multicolumn{1}{|c|}{ Bloque de contenidos } & $\begin{array}{c}\text { Representación en } \\
\%\end{array}$ \\
\hline Bases teóricas de la mediación & $48 \%$ \\
\hline Conflictología y ADR & $19 \%$ \\
\hline Ámbitos de aplicación de la mediación. & $16 \%$ \\
\hline Metodología de Intervención (Prácticas) & $11 \%$ \\
\hline Planificación e investigación en mediación. & $6 \%$ \\
\hline
\end{tabular}

Fuente: Elaboración Propia

\footnotetext{
${ }^{4}$ Una acción formativa homologada en el Centre de Mediació y Dret Privat de Catalunya otorga a los egresados la acreditación para ingresar en el Registro Público de mediadores de la comunicad de Cataluña y les habilita para su ejercicio profesional. Información recogida en la Ley 15/2009, de 22 de julio, de mediación en el ámbito del derecho privado, de la Comunidad Autónoma de Cataluña.
} 
Como podemos ver en la Tabla 2, el bloque más representado es el relativo a las Bases teóricas de la mediación, que comprende los siguientes contenidos:

- Deontología. Hace referencia al comportamiento del mediador en cuanto a su profesión, su actuación en determinados casos y a su comportamiento durante la ejecución de la actividad profesional mediadora.

- Mediación-Mediador. Hace referencia al concepto de mediación como método alternativo de resolución de conflictos comprendido en los denominados Alternative Dispute Reolutions (en adelante ADR). Incluye los principios de la mediación y lo que la diferencia de otros procesos de gestión de conflictos. Así mismo, este bloque incluye el concepto de mediador como profesional que gestiona y dirige el proceso de mediación. Determina sus habilidades y técnicas principales, así como su identidad profesional particular basada en aspectos como la imparcialidad y la neutralidad.

- Comunicación. La comunicación, como elemento fundamental en el proceso de mediación. Este bloque hace referencia a las habilidades comunicadoras de la persona mediadora, a estrategias transformadoras que aplicar a las partes y a los elementos necesarios en la comunicación que permitirán el entendimiento, legitimación, colaboración y gestión del conflicto por parte de las partes implicadas en el mismo.

- Proceso de mediación, habilidades y técnicas. Este bloque de conocimientos hace referencia a las fases del proceso de mediación y a los objetivos a perseguir en cada una de ellas. Partiendo de las aportaciones de Moore (1995) hasta las recomendaciones recogidas en la normativa que permiten un reconocimiento del proceso que garantiza su reconocimiento social $\mathrm{y}$ jurídico, el proceso de mediación se compone de una serie de fases o etapas por las que el mediador ha de guiar a las partes.

- Historia. El bloque de marco histórico presenta en las formaciones específicas sobre mediación una trayectoria evolutiva de los métodos de gestión de conflictos. Recoge métodos que a lo largo de la historia se han desarrollado y los plantea con los actuales ADR. Así mismo, este bloque presenta los orígenes americanos de la mediación, el desarrollo europeo y las primeras experiencias españolas.

- Marco jurídico. Este bloque de conocimientos se centra en la actualidad normativa de la mediación, no sólo en el contexto español, sino también en el europeo. De este bloque destaca la normativa respecto a la figura de la persona mediadora, la práctica de la mediación, el reconocimiento de la mediación en el ámbito intrajudicial y la validez del proceso mediador y de los acuerdos de mediación desde la perspectiva legal.

- Modelos de mediación. Como en otras disciplinas como el Trabajo Social, el procedimiento metodológico de intervención presenta diferentes perspectivas y ejecuciones según el modelo que apliquemos a cada caso. En la mediación "disponemos de tres modelos fundamentales", como indican 
Munné y MacCragh (2006:68) que además han originado otros a partir de sí mismos, estos modelos son el Modelo de Harvard de Fisher y Ury (1981), el Modelo Transformativo de Bush y Folger (1996), y el Modelo CircularNarrativo de Sara Cobb (Munuera, 2007).

La Tabla 2 muestra que el segundo bloque con mayor representación es el referido a Conflictología y $A D R$, que comprende los siguientes contenidos:

- Definición de Conflicto. Incluye las teorías del conflicto, la concepción del conflicto desde la perspectiva transformadora que lo entiende como oportunidad de cambio, así como las diferentes teorías que indican sus componentes. Así mismo se estudia el conflicto y sus dimensiones como ente que afecta en la dimensión inter-personal, intra-personal, intra-grupal e inter-grupal.

- Impacto del conflicto en las relaciones humanas desde la perspectiva psicosocial. Este bloque trata las repercusiones psico-sociales del conflicto, sus implicaciones intrapersonales y su impacto en las relaciones personales.

- ADR. Los métodos alternativos de resolución de conflictos como modelos de gestión alternativa de los mismos que ofrecen una visión más amplia, más allá del clásico Sistema Judicial. Estos ADR son el arbitraje, la conciliación, la negociación y la mediación. La mediación posee características particulares que la distinguen y diferencian del resto de ADR, pero todos ellos están unidos por la idea común de ofrecer un modelo de gestión de conflictos donde las partes adquieren más presencia.

El tercero de los bloques de conocimientos que se recogen en las ofertas formativas catalanas y que, como se observa en la Tabla 2 , representa el $16 \%$ de los contenidos es el referido a los ámbitos de aplicación de la mediación, o espacios especializados de ejecución del proceso mediador. Los principales espacios en los que se forman los estudiantes de mediación en Cataluña son:

- Mediación comunitaria. Aquella mediación aplicada a conflictos derivados de la convivencia social. Las actuales leyes denominadas integrales introducen este espacio y lo regulan otorgándole relevancia y reconocimiento. Así mismo, las leyes integrales sientan las bases para la creación de servicios públicos de mediación comunitaria con el objetivo de la paz social y la convivencia vecinal.

- Mediación mercantil o empresarial. Este espacio se introduce en España de la mano de la Ley 5/2012 de Mediación en asuntos civiles y mercantiles. Este espacio específico permite la aplicación de la mediación como método de resolución de conflictos en el entorno empresarial y comercial. Sus aplicaciones son diversas: gestión de personal, facilitación de equipos, relaciones comerciales y relaciones empresariales entre otros. Este espacio requiere una formación específica y conocimientos empresariales que 
permitan la determinación de idoneidad de la mediación como método eficaz de gestión del conflicto en la empresa.

- Mediación Familiar. El espacio más desarrollado en España, pues las primeras iniciativas sobre mediación ejecutadas en España se aplican al ámbito de la familia, especialmente en casos de separación o divorcio. El componente emocional de los conflictos familiares hace necesaria una formación potente. Así mismo este espacio se desarrolla en el ámbito intrajudicial, siendo necesaria pues la formación en procedimientos jurídicos de los mediadores que intervendrán en la gestión del conflicto.

El cuarto de los bloques representados en el Gráfico 2 es el referido a la Metodología de intervención o apartado de ejecución práctica. Este bloque incluye formación para la ejecución de las funciones de la persona mediadora, en relación con la preparación del caso, conducción durante el proceso de mediación, ejecución de las habilidades y técnicas y cierre y seguimiento del caso. Este entrenamiento práctico incluye la capacidad de determinar la pertinencia de la mediación según el conflicto, de determinar los implicados directos, así como de determinar el modelo teórico de la mediación más adecuado en cada caso. Tras el estudio de este bloque y su presencia en la oferta formativa universitaria en Cataluña destacamos tres importantes datos:

- La mayor parte de las ofertas formativas analizadas no alcanzan los mínimos establecidos en la norma estatal respecto a la formación específica en conceptos prácticos. Sin embargo identificamos este apartado confuso pues la misma norma que determina la cuantía mínima de formación práctica no especifica detalladamente qué se considera formación práctica, por lo que es difícil identificarla en las acciones formativas estudiadas.

- Hemos detectado que de las 19 ofertas formativas estudiadas 10 de ellas hacen referencia a un módulo específico de formación práctica, aunque sin especificar con detalle el contenido del mismo.

- De las 19 ofertas formativas analizadas, hemos identificado 2 que son formación eminentemente práctica de menor duración (18 ECTS) y que se conciben como complemento a formaciones teóricas previas.

El bloque con menor representación reflejada en la Tabla 2 es el que hace referencia a la Planificación e Investigación en mediación. Este bloque incluye formación en técnicas de investigación, redacción de proyectos o proyección de instituciones de mediación y se materializa a través de los denominados Trabajo Fin de Título, necesarios para la culminación de los estudios y la adquisición de títulos en el EEES.

\section{- Relación entre la construcción empírica y la realidad formativa}

Como recogíamos anteriormente en la Tabla 1, los expertos en la materia nos indican una serie de conocimientos que consideran deben ser abordados en la formación específica en mediación que resultan ser bastante similares a los 
recogidos en las ofertas formativas catalanas. De la combinación de la propuesta de expertos con la información obtenida del estudio de la actualidad formativa en materia de mediación en Cataluña extraemos las siguientes relaciones:

\section{Tabla 3. Relación entre contenidos propuestos por expertos y realidad formativa}

\begin{tabular}{|c|c|c|}
\hline $\begin{array}{c}\text { Bloque de } \\
\text { Conocimientos }\end{array}$ & $\begin{array}{c}\begin{array}{c}\text { Contenidos propuestos por } \\
\text { expertos }\end{array} \\
\end{array}$ & $\begin{array}{c}\text { Contenidos recogidos en la } \\
\text { Oferta Formativa }\end{array}$ \\
\hline \multirow{3}{*}{$\begin{array}{l}\text { Bases Teóricas } \\
\text { de la } \\
\text { Mediación }\end{array}$} & -Teorías de la comunicación & Comunicación \\
\hline & $\begin{array}{l}\text {-El proceso de mediación y sus } \\
\text { fases }\end{array}$ & $\begin{array}{l}\text { Fases de la mediación, habilidades } \\
\text { y técnicas }\end{array}$ \\
\hline & $\begin{array}{l}\text {-Estudio de los diferentes Códigos } \\
\text { de Conducta a partir de la } \\
\text { normativa europea. }\end{array}$ & Deontología \\
\hline \multirow{5}{*}{$\begin{array}{l}\text { Conflictología } \\
\text { y ADR }\end{array}$} & -Teorías del conflicto & \multirow{4}{*}{$\begin{array}{l}\text { Definición del conflicto, estilos } \\
\text { personales de gestión, teorías y } \\
\text { dimensiones. }\end{array}$} \\
\hline & -Ciclo del conflicto & \\
\hline & -Componentes del conflicto & \\
\hline & $\begin{array}{l}\text {-Estilos de afrontamiento de los } \\
\text { conflictos }\end{array}$ & \\
\hline & $\begin{array}{l}\text {-Estrategias de gestión de } \\
\text { conflictos }\end{array}$ & Los ADR \\
\hline $\begin{array}{l}\text { Ámbitos de } \\
\text { aplicación de la } \\
\text { Mediación. }\end{array}$ & $\begin{array}{l}\text {-Familia como espacio } \\
\text { predominante pero interés en } \\
\text { nuevos espacios según demanda } \\
\text { social. }\end{array}$ & $\begin{array}{l}\text { Mediación comunitaria, civil, } \\
\text { mercantil y familiar. }\end{array}$ \\
\hline \multirow{3}{*}{$\begin{array}{l}\text { Metodología de } \\
\text { Intervención } \\
\text { (Prácticas) }\end{array}$} & -Análisis de supuestos prácticos & \multirow[b]{2}{*}{$\begin{array}{l}\text { Prácticas, aplicación de la } \\
\text { metodología }\end{array}$} \\
\hline & $\begin{array}{l}\text {-Habilidades de mediación como: } \\
\text { escucha activa, comunicación } \\
\text { eficaz, imparcialidad, neutralidad. }\end{array}$ & \\
\hline & $\begin{array}{l}\text {-Diferencias y similitudes entre el } \\
\text { mediador y otros profesionales }\end{array}$ & Evaluación profesional \\
\hline \multirow{3}{*}{$\begin{array}{l}\text { Planificación e } \\
\text { Investigación }\end{array}$} & -Habilidades de trabajo en equipo & \multirow[t]{3}{*}{ Hipótesis sobre el conflicto } \\
\hline & -Trabajo en equipo multidisciplinar & \\
\hline & -Planificación de la intervención & \\
\hline
\end{tabular}

Fuente: Elaboración Propia

Como observamos en la Tabla 3, existe una estrecha relación entre los contenidos propuestos por los expertos y los que recogen las ofertas formativas estudiadas. Observamos importantes solicitudes entre las consideraciones académicas y la oferta formativa como evidenciamos en la Tabla 3. A pesar de la similitud, observamos algunos puntos de divergencia respecto a los ámbitos específicos de aplicación de la mediación y a la formación para el trabajo en equipo multidisciplinar. Al respecto de los ámbitos específicos de aplicación de la mediación, los expertos no determinan el ámbito o ámbitos 
concretos que debe recoger una formación específica en mediación, sin embargo en la oferta formativa actualmente vigente observamos que siempre se destina un porcentaje importante de la formación al estudio de un ámbito específico, siendo en Cataluña el más popular el ámbito comunitario, tras el civil, mercantil y el familiar.

Otro aspecto de diferencia es que identificamos contenidos en las actuales ofertas formativas que no son recogidos por los expertos, como la formación en técnicas de investigación o en el desarrollo y coordinación de una institución de mediación.

A pesar de los espacios de divergencia, tras esta comparativa podemos suponer que existe relación estrecha y cierto consenso en cuanto a los contenidos precisos en una acción formativa específica en mediación desde la perspectiva de los expertos y la realidad formativa.

\section{- Referencia a las competencias para el ejercicio mediador en la formación actualmente vigente en Cataluña.}

Las competencias son la referencia para establecer las líneas o directrices de una acción formativa, ya que los contenidos que ésta aglutina deben ser conducentes a la adquisición de las mismas. Las aportaciones de Martínez et al. (2008) evidencian que es importante definir las competencias vinculadas con cada perfil profesional, constituyendo estas el conjunto de conocimientos, competencias y funciones que se desarrollan al final de un proceso formativo, y que permitirán a la persona manejarse con éxito en diferentes situaciones de su quehacer laboral a lo largo de su proyecto profesional.

De las 19 acciones formativas que se imparten en las universidades catalanas, sólo en 6 de ellas se recoge en la guía de título la referencia a las competencias que adquirirán los estudiantes en las diferentes materias que componen la acción formativa específica en mediación. Los 6 títulos vigentes en el curso académico 2015-2016 que recogen las referencias a las competencias pertenecen a dos universidades, la Universitat Autónoma de Barcelona (UAB) con cinco títulos formativos específicos en mediación y la Universitat de Barcelona (UB) con un título formativo específico en mediación. Del estudio de estos títulos identificamos las siguientes competencias generales y específicas:

- Competencias Generales: Habilidad para el trabajo en equipo. Capacidad para aplicar las nuevas tecnologías de la información y la comunicación en el ámbito académico, profesional y de intervención. Habilidades para saber evaluar la prueba científica que sustenta las afirmaciones y las intervenciones propias de la profesión. Capacidad para respetar la diversidad humana y para mostrar un compromiso ético en el ejercicio profesional

- Competencias Específicas: Habilidad para analizar, evaluar y diseñar intervenciones mediadoras o formativas en el marco de la prevención, la gestión y la transformación del conflicto y para identificar factores de riesgo que promuevan y mantengan los conflictos. Habilidades en el uso de estrategias y técnicas mediadoras en la prevención y gestión de conflicto en el ámbito de la mediación familiar y comunitaria y de la mediación mercantil y de las organizaciones. Habilidades comunicativas efectivas para prevenir y 
gestionar conflictos y para poder aplicar metodologías y procedimientos de búsqueda relacionados con los procesos de mediación y otras intervenciones mediadoras. Capacidad para identificar las propias limitaciones y las de los otros para mejorar la eficacia de los procesos de mediación o de formación en mediación.

A partir de la información adquirida nos parece de interés para el desarrollo de este trabajo y el de la mediación como disciplina emergente realizar una comparativa entre las propuestas extraídas desde el ámbito académico y los expertos y la información recogida en los títulos formativos propuestos desde el ámbito formativo siguiendo las recomendaciones del Proyecto Tuning anteriormente referido que propone una formación superior que asocie la academia con la docencia además de las necesidades del ejercicio profesional. 


\section{Tabla 4 Competencias propuesta propuestas por expertos y realidad formativa}

\begin{tabular}{|c|c|c|}
\hline $\begin{array}{c}\text { Área } \\
\text { Competencial }\end{array}$ & Competencias de los expertos & $\begin{array}{l}\text { Competencias en la actualidad } \\
\text { formativa }\end{array}$ \\
\hline $\begin{array}{l}\text { Competencias } \\
\text { Generales }\end{array}$ & $\begin{array}{l}\text { Aquellas que permiten al individuo } \\
\text { ser activo en cuanto al aprendizaje } \\
\text { y al desarrollo de su actividad } \\
\text { educativa y profesional: } \\
\text {-Conocimiento de las variables de } \\
\text { la comunicación } \\
\text {-Comprensión de los beneficios de } \\
\text { la colaboración de las diferentes } \\
\text { áreas de conocimiento. } \\
\text {-Dominio de la Planificación } \\
\text {-Comprensión, análisis, crítica y } \\
\text { estudio. } \\
\text {-Adaptación de la teoría a la } \\
\text { práctica. }\end{array}$ & $\begin{array}{l}\text { Habilidad para el trabajo en equipo. } \\
\text { Capacidad para aplicar las nuevas } \\
\text { tecnologías de la información y la } \\
\text { comunicación en el ámbito } \\
\text { académico, profesional y de } \\
\text { intervención. Habilidades para } \\
\text { saber evaluar la prueba científica } \\
\text { que sustenta las afirmaciones y las } \\
\text { intervenciones propias de la } \\
\text { profesión. Capacidad para respetar } \\
\text { la diversidad humana y para } \\
\text { mostrar un compromiso ético en el } \\
\text { ejercicio profesional }\end{array}$ \\
\hline $\begin{array}{l}\text { Competencias } \\
\text { específicas }\end{array}$ & $\begin{array}{l}\text { Aquellas que permiten al individuo } \\
\text { aprender la profesión de la } \\
\text { mediación en cuanto a base teórica } \\
\text { y práctica. } \\
\text {-Dominio del conflicto } \\
\text {-Capacidad para desarrollar el } \\
\text { proceso de mediación, sus fases y } \\
\text { sus protocolos de actuación. } \\
\text {-Ejecución de las habilidades y } \\
\text { técnicas del mediador } \\
\text {-Desempeño del rol de mediador. } \\
\text {-Distinción de roles con respecto a } \\
\text { otras disciplinas. } \\
\text {-Respeto del código ético } \\
\text { reconocido. }\end{array}$ & $\begin{array}{l}\text { Habilidad para analizar, evaluar y } \\
\text { diseñar intervenciones mediadoras } \\
\text { o formativas en el marco de la } \\
\text { prevención, la gestión y la } \\
\text { transformación del conflicto y para } \\
\text { identificar factores de riesgo que } \\
\text { promuevan y mantengan los } \\
\text { conflictos. Habilidades en el uso de } \\
\text { estrategias y técnicas mediadoras en } \\
\text { la prevención y gestión de conflicto } \\
\text { en el ámbito de la mediación } \\
\text { familiar y comunitaria y de la } \\
\text { mediación mercantil y de las } \\
\text { organizaciones. Habilidades } \\
\text { comunicativas efectivas para } \\
\text { prevenir y gestionar conflictos y } \\
\text { para poder aplicar metodologías y } \\
\text { procedimientos de búsqueda } \\
\text { relacionados con los procesos de } \\
\text { mediación y otras intervenciones } \\
\text { mediadoras. Capacidad para } \\
\text { identificar las propias limitaciones } \\
\text { y las de los otros para mejorar la } \\
\text { eficacia de los procesos de } \\
\text { mediación o de formación en } \\
\text { mediación. }\end{array}$ \\
\hline
\end{tabular}


Fuente: Elaboración Propia

Detectamos ciertas similitudes y un núcleo común entre las propuestas desde el ámbito académico y el ámbito formativo, esto puede suponer el punto de partida para la creación de modelos educativos por competencias unificados y reconocidos que contribuirán a la configuración sólida del gremio y a la identificación social de la profesión mediadora.

Las competencias planteadas en las ofertas formativas universitarias denotan un rol profesional que ha de ejecutar acciones que le permitan un trabajo en equipo, que base sus procedimientos de actuación en el modelo científico y que tenga en todo momento presente la cuestión ética y deontológica durante la ejecución de su rol. Así mismo, identificamos un profesional capaz de analizar, evaluar, prevenir, intervenir y gestionar situaciones de conflicto para transformarlas en oportunidades de mejora en el ámbito familiar, comunitario o mercantil. El profesional de la mediación debe poseer habilidades comunicativas y tener competencias para su desarrollo y para favorecer la adquisición de las partes implicadas, además ha de valorar la formación continua con el objeto de mejorar la eficacia de sus intervenciones.

El perfil competencial que se describe desde las universidades catalanas muestra un profesional específico, determinado y diferenciado de otras profesiones. Este perfil marca la meta que ha de conseguirse mediante el diseño de una acción formativa que garantice la adquisición de estas competencias.

\section{Discusión y Conclusiones}

La definición de mediador recogida en la literatura describe un profesional eficaz y eficiente capaz de aplicar habilidades y técnicas según la tipología de caso en la que intervenir y además competente para proyectar la mediación como modelo de intervención para la gestión de conflictos y desarrollar las metodologías teóricoprácticas que permitan el crecimiento de esta disciplina. El conjunto de profesionales de la mediación debe ser capaz, de forma similar, de aplicar y proyectar la mediación de modo que han de poseer competencia similares y para ello será necesario un sistema que proponga, homogeneice, controle y evalúe las competencias para el ejercicio profesional, los contenidos a estudiar, las habilidades a adquirir y la preparación para los diferentes espacios especializados de esta disciplina emergente.

\section{- Consenso en la composición teórico-práctica entre las ofertas formativas específicas en mediación y la actualidad empírica.}

La actualidad formativa en materia de mediación presenta unas características comunes básicas aportadas por la normativa reguladora, pero incorpora aspectos variables según el tipo de formación cursada que puede suponer diferencias en la adquisición de las competencias precisas para el ejercicio profesional mediador. 
Este hecho requiere conocer detalladamente la composición de la oferta formativa actualmente impartida para identificar los puntos de convergencia y de divergencia.

El análisis de la actualidad formativa catalana en materia de mediación nos muestra una relación estrecha entre la perspectiva de los expertos respecto al contenido teórico de una acción formativa específica sobre mediación y la realidad formativa en Cataluña. Esto quizás pueda deberse a que Cataluña, como comunidad pionera en materia de mediación, ha conseguido una convergencia en cuanto a la evolución teórica y la formativa que ha derivado en ofertas formativas ajustadas a los avances teóricos en la materia. Es cierto que percibimos ciertos puntos en los que no se produce ese acuerdo, como es el caso de los ámbitos específicos de formación en mediación o la capacitación para la investigación y el trabajo multidisciplinar. Respecto al primer punto, podemos presumir que se trata de un elemento que varía según el criterio de la entidad formativa que podría decidir dicho ámbito en función de la realidad social y la evolución de la mediación a nivel normativo. En el caso de la mediación familiar, es un ámbito bastante desarrollado y regulado por lo que es habitual encontrarlo en ofertas formativas. El ámbito civil y mercantil es un espacio más reciente que necesita consolidarse en cuanto a regulación y definición para poco a poco ir incorporándose en las acciones formativas.

El otro punto en el que identificamos divergencia es en cuanto a la formación para el trabajo en equipo multidisciplinar y la investigación. Presumimos que esto se debe a que si bien los expertos proponen esta formación como elementos necesarios para la profesionalización de la persona mediadora, es precisamente la consideración de esta profesionalización la que todavía no se ha trasladado a las ofertas formativas. En este caso probablemente hay mayor desarrollo empírico que abordaje en el campo formativo.

Para concluir este apartado, podemos decir que este consenso entre la percepción experta y la realidad docente facilita enormemente la construcción formativa en materia de mediación ya que, al considerarse necesarios los puntos anteriormente descritos por ambas esferas (teórica y formativa) esto puede hacer surgir un marco no formal pero sí consensuado para el diseño de ofertas formativas en materia de mediación que probablemente conduzca a una homogeneización de la formación específica en la materia. Así mismo, podríamos considerar este consenso como el primer paso a tener en cuenta para la elaboración de un currículo o Libro Blanco de referencia que podría tener impacto a nivel estatal.

\section{- La incidencia de la formación en mediación en las universidades catalanas}

La mediación es una actividad profesional emergente que actualmente experimenta una importante revisión teórica que permite la aportación de cimientos teóricos a esta acción profesional. El desarrollo de la mediación como intervención para la resolución de conflictos debe acompañarse de una estructuración teórica de ésta como disciplina, lo que supone el impulso de acciones investigadoras de carácter teórico cuyos resultados, logros y avances contribuyen a la consolidación de la mediación. Además de la investigación teórica, resulta necesaria una revisión respecto al rol diferenciado de la persona mediadora en relación con la ejecución de su intervención. Este hecho marca la necesidad de estudiar y diferenciar las 
funciones específicas de la persona mediadora y determinar las competencias precisas para la correcta ejecución de las mismas. Es por esto que resulta relevante poner interés a la capacitación, entrenamiento y formación del conjunto de mediadores, para así impulsar la formación específica en mediación y con ello favorecer la consolidación de la mediación como profesión y disciplina.

La mediación es una disciplina cuyos programas formativos pertenecen predominantemente a la formación superior. El EEES introduce la idea de proporcionar un aprendizaje homogeneizado en Europa y un sistema basado en la adquisición de unos conocimientos para generar aptitudes que conviertan al futuro profesional en competente.

Del estudio realizado, podemos concluir que el impacto del sistema de aprendizaje por competencias es poco visible en el ámbito de la enseñanza de la mediación en Cataluña pues únicamente dos de las siete entidades universitarias incluye la descripción de las competencias en los títulos específicos de mediación. Este hecho muestra que la construcción de las ofertas formativas no posee un sistema competencial de referencia para su diseño, sino que son otros factores los que determinan dicha composición. Puede considerarse la Ley de mediación 5/2012 y el Real Decreto 980/2013 que la regula como uno de estos factores influyentes en la construcción de las acciones formativas específicas en mediación. Sin embargo, estas normativas muestran únicamente unas líneas básicas a tener en cuenta, por lo que no suponen la referencia curricular que el conjunto formativo en materia de mediación precisa.

\section{- Impacto de este estudio en el desarrollo de la mediación en España}

La mediación, como disciplina emergente, precisa constructo teóricos básicos que sienten las bases para la investigación, la intervención y la docencia. Este estudio muestra aspectos esenciales para conocer la situación actual de la formación específica en mediación en una de las ciudades pioneras en España.

El estudio muestra que la universidad se erige como entidad formativa predominante, por lo que la formación en mediación ha de ejecutarse desde los parámetros de la educación superior. Para ello, los programas de formación en mediación deben construirse bajo el prisma del sistema de aprendizaje por competencias, competencias precisas para la intervención mediadora que será necesario identificar, clarificar, contrastar, agrupar y proponer para que sirvan de orientación en la planificación de las acciones formativas. Este estudio tiene como objetivo identificar la presencia de las competencias en las acciones formativas actualmente vigentes en las universidades catalanas. Los principales datos determinan que las acciones formativas en mediación se han construido a partir de iniciativas personales (de expertos), a partir de aportaciones extranjeras (planes de estudios de universidades extranjeras) o en base a las recomendaciones recogidas en la normativa vigente al respecto. Este hecho muestra una construcción formativa que carece de un sistema curricular vertebrador que facilite una formación homogénea en nuestro país. Hecho que repercute directamente en el conjunto de mediadores profesionales pues éstos representarán un colectivo diverso y con una percepción o identidad profesional difusa. 
Este estudio muestra la carencia de un sistema competencial unificador, pero identifica las fortalezas y oportunidades que presenta el conjunto formativo presente en Cataluña a partir de los puntos comunes, las coincidencias y las similitudes que hasta ahora se desarrollan.

La definición de las competencias permite la construcción diferenciada de una acción profesional, de un rol, de un perfil profesional. Esta construcción diferenciada infiere directamente en la visión social del perfil profesional mediador $\mathrm{y}$ en la diferenciación de otros perfiles afines. Esta diferenciación profesional y el reconocimiento social favorecen directamente la consolidación de la mediación como disciplina y estrategia de intervención social, hecho que favorecerá su arraigo y presencia en la sociedad española. Esta situación es deseable concretamente en mediación debido a que se trata de una profesión emergente que precisa un reconocimiento social que debe partir desde la homogeneización formativa para conseguir un gremio estable, diferenciado y competente que ejecute de forma eficaz su tratamiento de los conflictos sociales.

\section{Referencias bibliográficas}

Barush Bush, R. A. y Folger, J. P. (1996). La promesa de la Mediación. Cómo afrontar el conflicto a través del fortalecimiento propio y el reconocimiento de los otros. España: Granica.

De Juanas Oliva, A. y Fernández Lozano, M. P. (2008). Competencias y estrategias de aprendizaje. Reflexiones sobre el proceso de cambio en el EEES. Cuadernos de Trabajo Social, (21), pp. 217-230.

Echeverría, B. (2005). Competencia de acción de los profesionales de la orientación. Madrid: ESIC.

Fisher, R., Ury, W., y Patton, B. (1981). Obtenga el sí. El arte de negociar sin ceder. Canadá: Penguin Books

Folberg, J. y Taylor, A. (1996). Mediación, resolución de conflictos sin litigio. México DF:Limusa.

García Villaluenga, L. y Bolaños Cartujo, I. (2007). Situación de la mediación familiar en España. Detección de necesidades, desafíos pendientes. Madrid: Ministerio de Trabajo y Asuntos Sociales.

González, J. y Wagenaar, R. (2003). Tuning educational structures in Europe. Informe Final. Fase Uno. Bilbao: Universidad de Deusto -University of Groningen.

Gorjón Gómez, F. J. y Sáenz López, K.A. (2014). Aprendizaje de los métodos alternos de solución de controversias mediante el modelo de competencias. Revista Lugares de Educaçao , 4, (9), pp. 234-251.

Martínez Clares, P., Martínez Juárez y M; Muñoz, M. (2008). Aprendizaje por competencias en educación superior. Revista Galego-Portuguesa de Psicoloxia e educación. 16, (1-2), pp 193-213.

Marshall, P. (2006). Emotional competente and the mediator. ADR Bulletin, 9 (2), pp. 1-7.

Moore, C. (1995). El proceso de Mediación. Barcelona: Granica. 
Munné, M. y Mac-Cragh, P. (2006). Los 10 principios de la cultura de la mediación. Barcelona: Graó.

Munuera Gómez, P. (2007). El modelo circular narrativo de Sara Cobb y sus técnicas. Portularia, 7, (1-2), pp. 85-106.

Pastor Seller, E. y Huertas Pérez, E. (2012). La mediación penitenciaria como método alternativo de resolución de conflictos entre internos en el ámbito penitenciario. Entramado, 8 (2), pp. 138-153.

Pastor Seller, E. e Iglesias Ortuño, E. (2011). La mediación intrajudicial como método de resolución de conflictos en el seno familiar. Entramado, 7 (1), pp. 72-87.

Rondón García, L. M. (2012). Bases para la mediación familiar. Valencia: Tirant LoBlanc. 